\title{
Technology Epiphany and an Integrated Product and Service
}

\author{
Satoru Goto*
}

\begin{abstract}
This study aims at exploring how an integrated product and service contributes to achieving Innovation of Meaning (IoM) or technology epiphany. Existing IoM studies have focused on intended meaning (as defined in new product development) and ignored the received meaning that users reconstruct. The process by which a user assigns meaning to things can not only be static but also dynamic. This study focuses on integrated products and contexts offered by services and analyses the case of Japan's largest manufacturer of ankle-foot orthoses. The results show that the service guides the users to reconstruct the meaning in dynamic cognitive processes and use the metaphors that contribute to the consistency between products and services.
\end{abstract}

Keywords: innovation of meaning; technology epiphany; service; context; emotion

Submitted: April $26^{\text {th }} 2017$ / Approved: July $4^{\text {th }} 2017$

\section{Introduction}

Innovation of meaning (IoM) is emerging as a new focal point in the innovation management discourse (Verganti, 2008; Kembaren, Simatupang, Larso, \& Wiyancoko, 2014; Farhana \& Bimenyimana, 2015). Verganti (2011) suggested that firms driven by design build and nurture a competitive advantage through a combination of radical changes in technologies and meanings; he defined such a combination as technology epiphany. In the existing marketing literature, Levy (1959, p. 118) emphasized that 'People buy things not only for what they can do but also for what they mean'. Moreover, Krippendorf (1989) suggested that creating a product meaning is a crucial issue of design, defining it as 'design is making sense (of things)'. Thus, te chnology epiphany is the one of the challenges beyond the traditional view of technological innovation as a driver of advancement in product performance (Simoni, Cautela, \& Zurlo, 2014).

Recently, many studies have attempted to understand issues related to IoM: the categorization of IoM (Rampino, 2011), design research (Norman \& Verganti, 2014), the process of IoM (Kembaren et al., 2014; Verganti, 2017), and technology epiphany (Goto \& Ishida, 2014; Buganza, Dell'Era, Pellizzoni, Trabucchi, \& Verganti, 2015). Although these studies emphasize the importance of an intended meaning that companies develop in new product development (NPD), users reconstruct the meaning in the contexts in which they experience the product or service (Kazmierczak, 2003; Crilly, Moultrie, \& Clarkson, 2004). This poses a question to researchers, challenging them to further the understanding of the process to realize IoM. It is difficult to control reconstructed meanings by considering a single product because of the lack of context of use.

Context is defined as the 'information available to a particular person, and on a particular occasion, for use in the meaning-ascription process' (Kleine \& Kernan, 1991, p. 311). Such information is offered in service encounters, which consist of service evidences
(Shostack, 1984) and human-to-human interactions (Pacenti \& Sangiorgi, 2010). Bellini, Dell'Era, Frattini, and Verganti (2017) noted that the generation of a new meaning is the result of an interaction between customers and companies in the physical space of services. More specifically, when a radical technology emerges in the market, a company faces the challenge of explaining to customers how it works and what it means (Eisenman, 2013). Thus, the service should be designed to help users reconstruct the intended meaning of the product. This means that it may be important to synthesize the perspectives of NPD and new service development (NSD).

Despite the importance of a comprehensive study on products and services, no attempts have been made till date to study the relationship between technology epiphany and integrated products and services. Thus, this study seeks to address this gap by answering the following research questions:

- RQ1: How does company develop an integrated product and service under a consisted meaning?

- RQ2: How do users reconstruct a meaning based on their interaction with an integrated product and service?

This study pursues these goals by exploring a case study in the assistive products (APs) industry, particularly, the Japanese ankle-foot orthosis (AFO) industry. The APs industry is a recent focus of Inclusive design, which aims at reducing product-related stigma. Correia de Barros, Duarte, and Cruz (2011) noted that the aesthetics and stigma associated with APs discourage consumers to use them. To change the meaning attributed by people to the use of APs is a socio-technical challenge for companies in the industry. Thus, this paper contributes to the limited understanding of the role of an integrated product and service to achieve technology epiphany and provides practical guidance to develop this understanding in the APs industry.

*Department of Business Administration, Toyo Gakuen University, 1-26-3, Hongo, Bunkyo-ku, Tokyo, Japan, satoru.goto@tyg.jp 
The structure of the paper is as follows. The next section briefly investigates the existing literature on the definition of IoM and the role of services. This is followed by the research design and data analysis. Then, the paper presents a comprehensive model, including the relationship between IoM and a service, and the process of users' cognitive response.

\section{Definition of IoM}

A product's appearance bears both tangible features and intangible attributes. The tangible features are dictated by size, material, colour, shape, and texture, inter alia (Bloch, 1995). The tangible features communicate information regarding functionality, aesthetics, and symbolism (Eisenman, 2013). Consumers assess a product based on this set of information, as received and perceived by the senses (Crilly et al., 2004), and the intangible attributes of a product are related to this assessment.

The existing literature shows the three-dimensional segmentation of the intangible attributes of a product: aesthetic impression, semantic interpretation, and symbolic association (Crilly et al., 2004). Aesthetic impression describes aesthetics that appeal to the human senses. Semantic interpretation refers to a consumer's response to functionality, utility, mode of use, and other qualities. Symbolic association is described as the personal and social significance assigned by the user, by virtue of messages, symbols, culture, and meaning (Table 1 summarizes the other definitions, as found in the literature).

Verganti (2008) proposed a radical change of meaning as design driven innovation (DDI), defining meaning in a broader sense (e.g., emotional and symbolic value). Meanwhile, Rampino (2011) categorized the four different kinds of innovation driven by design as aesthetic innovation, innovation of use, meaning innovation, and typological innovation. Aesthetic innovation relates to aesthetic impression, innovation of use refers to semantic interpretation, and meaning innovation concerns symbolic association. Meaning innovation happens when form, mode of use, and technology are radically changed (Rampino, 2011), because all aspects of intangible attributes are highly interrelated (Crilly et al., 2004). Emotions may result from the radical change of these intangible attributes (Crilly et al., 2004). Thus, this study defines IoM in a narrow way as innovation of the meaning comprised in the symbolic aspect of a product.

Table 1. Three-dimensional segmentation of intangible attributes

\begin{tabular}{llll}
\hline & Aesthetic aspect & Functional aspect & Symbolic aspect \\
\hline Crilly, Moultrie, \& Clarkson (2004) & Aesthetic interpretation & Semantic interpretation & Symbolic association \\
\hline Candi (2006) & Visceral design & Functional design & Experiential design \\
\hline Rampino (2011) & Aesthetic & Of use & Meaning \\
\hline Eisenman (2013) & Aesthetic information & Functional information & \multirow{2}{*}{ Symbolic information } \\
\hline
\end{tabular}

\section{Meaning and service}

Users interpret products at two orders of meaning: first-order meaning and second-order meaning (Eisenman, 2013). First-order meaning refers to the immediate cognitive response to a product's appearance, and users compare the product to previous products, categorize, and understand it (Ulrich \& Eppinger, 2004). A radical change in the product's appearance discourages users to evaluate its impact on their first-order meaning and elicits strong positive or negative emotion (Rampino, 2011). Meanwhile, second-order meaning results from longer psychological processes in which users analyse the products using their memory accumulated in their cultural backgrounds and social settings. This second-order meaning may be changed by additional information related to a product (Eisenman, 2013). Given that companies aim at guiding users to reconstruct intended meanings to radically changed product appearances, especially in the case of technology epiphany, the companies maintain direct interactions with them to offer the additional information in their dynamic reconstruction processes. Services may be one of the useful ways to guide them in reconstructing the second-order meaning because they can build long-term relationships between companies and users. Moreover, human-to-human interactions may be an opportunity to share the intended meaning with users.
Dell'Era and Verganti (2011) noted that collaboration between producers within the same design discourse can help disseminate new meaning within an industry. Such collaboration helps a company that is developing new meaning to educate other companies about it; they communicate and share it during NPD. A service, on the other hand, is likely to offer to users education regarding a new meaning, because the company has an opportunity to communicate with users. Bellini et al. (2017) stressed that the meaning is affected by 'shopping experience', which is the multi-sensory interaction between consumers and salespersons that happens in the physical spaces of the store. Moreover, consumer engagement that refers to commitment, trust, selfbrand connection, and loyalty occurs within the dynamic, iterative process inherent in a service relationship (Brodie, Hollebeek, Juric, \& Ilic, 2011). Consumer engagement helps users co-create experience and value with companies. Above all, the service is likely to work as a way to affect the second-order meaning through the dynamic reconstruction process.

\section{Research framework}

Kembaren et al. (2014) suggested the conceptual framework of the process of DDI (Figure 1) and noted that storytelling has a strategic role to educate potential customers about a radical meaning. 
However, the storytelling does not accompany ongoing interactions with users and is, thus, likely to be the static for companies and customers. The process through which users reconstruct the intended meaning should be recognized as dynamic (Kazmierczak, 2003). In the dynamic process of cognitive response to an integrated product and service, product appearance is the first point of contact for users, making it usable as a stimulus to affect an ex-ante relationship quality, including affective variables such as trust, commitment, and satisfaction (Rha, 2012), because it can evoke positive or negative emotions in customers. Once customers experience a service encounter, companies can offer additional information related to products. Thus, they can affect second-order meaning in the context of use.

Figure 1. IoM (design driven innovation) process conceptual framework (Kembaren et al., 2014)

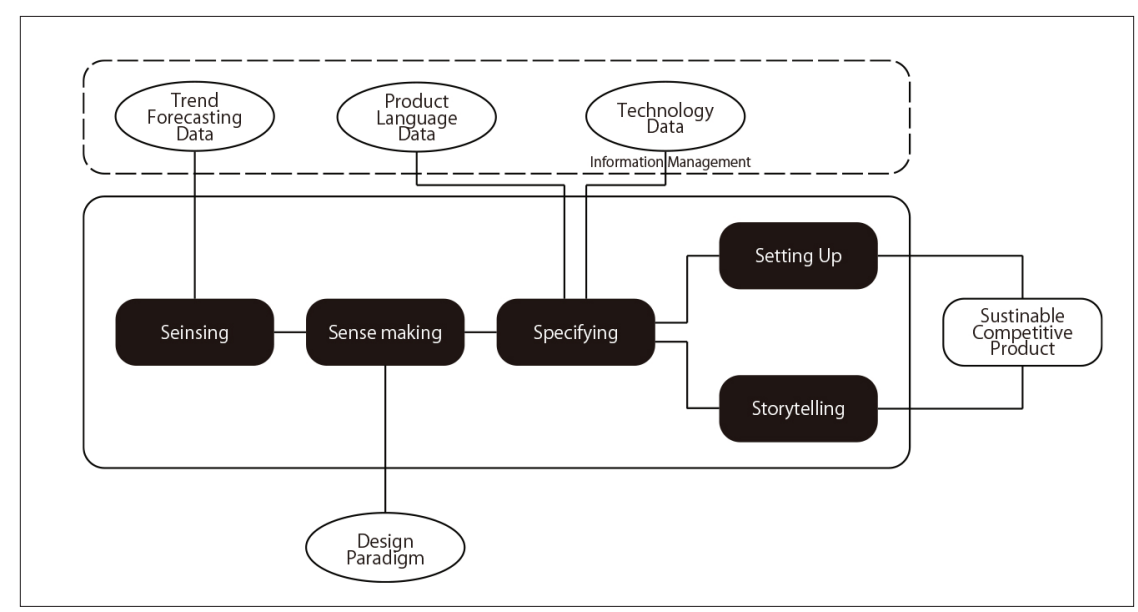

Based on the above literature review, the research framework is developed (see Figure 2). NPD consists of technology searching/development and product language design (Kembaren et al., 2014). Product language is defined as product appearance that conveys messages to users
(Verganti, 2008). Meanwhile, NSD consists of service package design and service interaction design (Buganza \& Verganti, 2005). Service package refers to the value the service delivers to users and service interaction refers to how it delivers value to them (Buganza \& Verganti, 2005).

Figure 2. Research framework (Adopted from Kembaren et al., 2014)

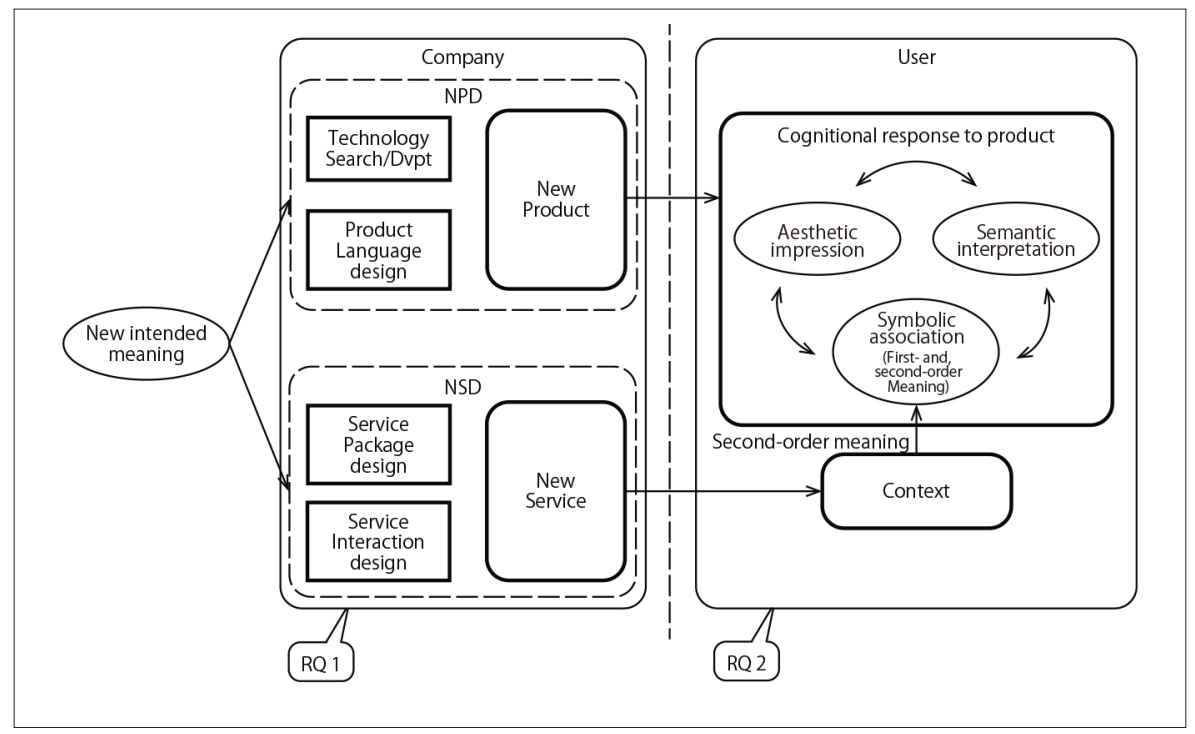

This study specifically focuses on two aspects. First, the study focuses on how designers consistently develop a product's appearance and service for the reconstruction of an intended meaning. Some literature on product service-systems (PSS) has suggested the design methodology to develop an integrated product and service. For example, Maussang, Zwolinski, and Brissaud (2009) argued that using scenarios during the development process is useful for engineering designers to understand the contexts that different people have. Morelli (2002) insisted that linking several social and technological factors is required to generate new technological frames, and designers need to extend their role to achieve this. These researches implied that during the development process of an integrated product and service, to clarify an intended meaning, context is needed to achieve technology epiphany. Second, as mentioned above, intangible product 
attributes result from users' cognitive response to a product's appearance in their contexts. Thus, this study also focuses on how products and services guide users to reconstruct intended meanings.

\section{Research design}

This study aims at answering two RQs, including the perspective of NPD and NSD and the perspective of the user's cognition process. We undertake an in-depth case study to appropriately to answer how or why in numerous levels of analysis (Yin, 1994)

When choosing appropriate and transparently observable cases, it is important to control for environmental variations (Eisenhardt, 1989). Therefore, we identified the common constructs of IoM. Tangible product attributes depend on technological features and social processes that surround their evolution (Pinch \& Bijker, 1987). Crilly et al. (2004) implied that once tangible attributes are solidified, the emphasis might shift to intangible ones. Moreover, Eisenman (2013) mentioned that intangible product attributes extend a product's basic functionalities; he also suggested that when new products emerge, their appearance acts as a tool that explains to users what they do. The design of intangible product attributes concerns itself with creating a 'bridge' between technical possibilities and market opportunities (Candi \& Samundsson, 2011). Therefore, having core technological competence is a basic competitive advantage.

Although the present study focuses on intangible attributes, it is difficult to evaluate their evolution, because they are very much contingent on customers' perceptions and interpretations. Therefore, this study refers instead to industrial designers' participation in new PSS development. Although the concept of industrial design has been defined in various ways (Verganti, 2008), it is agreed that it is responsible for a product's appearance and user-friendliness, among other things (Gemser \& Leenders, 2001; Pedgley, 2009). Gorb and Dumas (1987) determined a process by which non-designers are engaged in design. Regardless of industrial designers' participation in this process (or lack thereof), customers have cognitive responses that are driven by their perception of tangible product attributes (Crilly et al., 2004). However, Verganti (2003) stressed that the designer's competence is useful in changing meanings through product appearance. Therefore, his/her participation must be considered when controlling for environmental variables.

In summary, the two dimensions inherent in selecting a case-technological competitiveness as a tangible product attribute and industrial designer participation as an intangible one-form the basis of our typology (Figure. 3).
Figure 3. The criteria of case selection

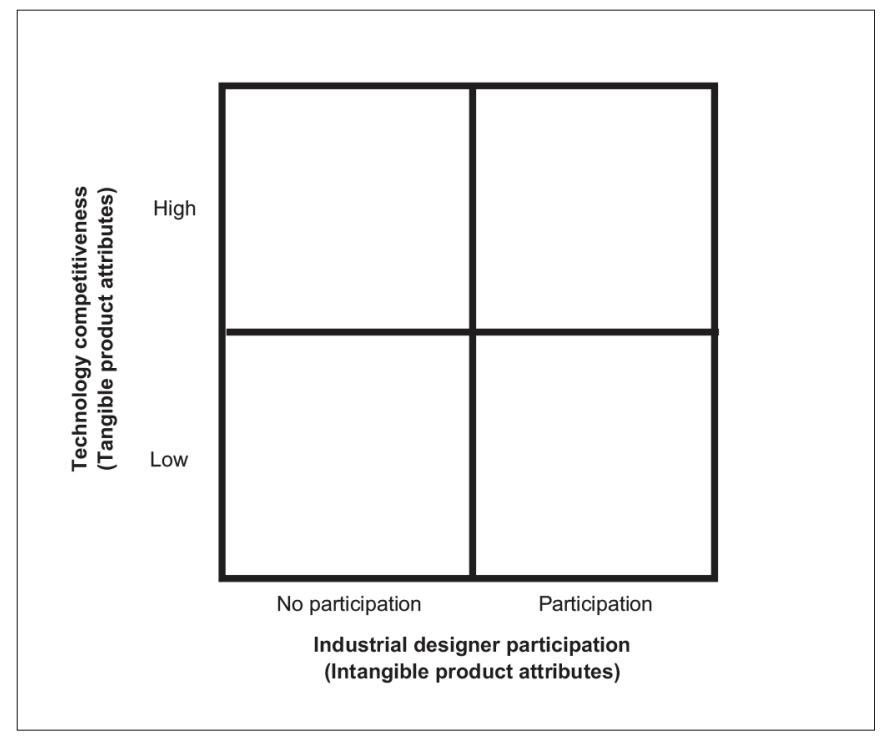

\section{Case selection}

Next, we focus on a narrower investigation area to reduce industry bias. This study employs a case from the Japanese AFO industry. Most customers in this industry periodically obtain public financial assistance to buy or lease durable medical equipment (DME), including AFOs. Therefore, price-competitiveness in this market is no more important than in other industries. Once customers buy or lease the DME, they keep it for a certain period. Moreover, most of the Japanese AFO companies have not employed designers to enhance the hedonic value of their products. Therefore, an examination of this industry can reveal the effect of a designer's participation on new PSS development processes.

In this study, we analysed the case of Kawamura Gishi Co., Ltd., Japan's largest manufacturer of AFOs. Kawamura Gishi offers both products as well as rehabilitation and related services. The company developed an innovative AFO called Gait Solution Design (GSD) by leveraging high-technology competitiveness (Figure 4). Its most unique feature-a hydraulic damper that can be adjusted through the use of a single tool-provides only minimal gait support and has received significant attention in the field of orthosis therapy. Moreover, in the development of the integrated product and service, Kawamura Gishi employed a design firm that has won various design awards.

However, prior to the design firm's participation, the company had developed GaitSolution (GS), which has the same function (a hydraulic damper) with GSD and sold only 10 GS in a month units; after launching GSD, the total sales of GS and GSD exceeded 300 units in a month. This means that high-technology competitiveness was not a driver in generating profits, and GSD's designer's participation in the development process had an impact on the company's sales (Figure 5). Thus, the present study theoretically selects this case as one that achieves technology epiphany. 
Figure 4. GS (left) and GSD (right)

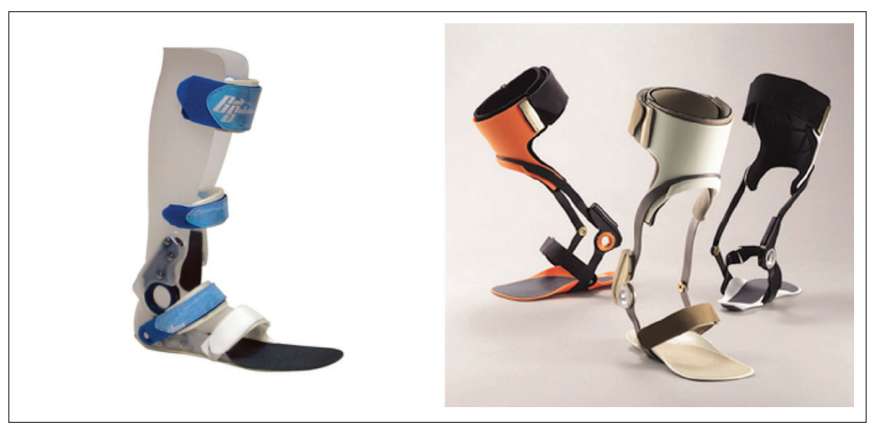

Figure 5. Case: Kawamura Gishi, Co., Ltd

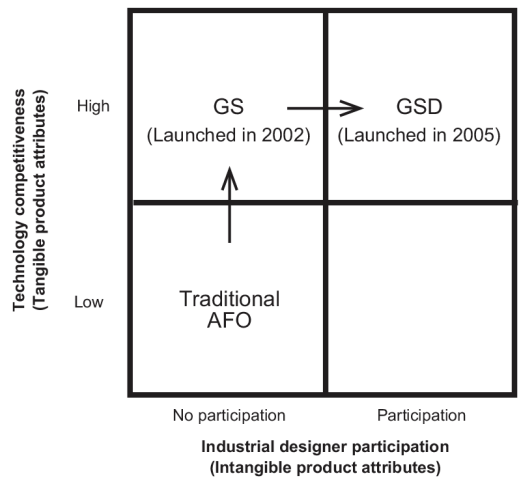

\section{Data collection}

This study combines data collected from multiple sources, interviews and archive sources. We conducted 14 semi-structured interviews at Kawamura Gishi and Pacific Supply Co., Ltd., a subsidiary company that carries other companies' products and services. Additionally, we interviewed the head designer at the design firm employed by Kawamura Gishi. Table 2 shows the profile of the interviewees. The interviews were conducted between June 2010 and December 2015; audio recordings of those interviews were captured, which were subsequently transcribed by two researchers.

Table 2. List of interviewees

\begin{tabular}{|c|c|c|c|}
\hline ID & Person & Department & Company \\
\hline 1 & Top executive & Management & Kawamura Gishi \\
\hline 2 & Chief engineer & Development & Kawamura Gishi \\
\hline 3 & Top executive & Management & Kawamura Gishi \\
\hline 4 & Manager & Sales & Kawamura Gishi \\
\hline 5 & Chief engineer & Development & Kawamura Gishi \\
\hline 6 & Division manager & Sales & Kawamura Gishi \\
\hline 7 & Manager & Manufacturing & Kawamura Gishi \\
\hline 8 & Division manager & Marketing and sales & Kawamura Gishi \\
\hline 9 & Top executive & Manufacturing & Kawamura Gishi \\
\hline 10 & Chief engineer & Development & Kawamura Gishi \\
\hline 11 & Top executive & Management & Kawamura Gishi \\
\hline 12 & Chief engineer & $\mathrm{R} \& \mathrm{D}$ & Kawamura Gishi \\
\hline 13 & Top executive & Wholesale & Pacific Supply \\
\hline 14 & Division manager & Development & Pacific Supply \\
\hline 15 & Assistant director & Design development & GK dynamics \\
\hline
\end{tabular}

\section{Data Analysis}

Technology search/development

An AFO is a device that assists hemiplegic patients who have an ankle disability. In the past, an AFO was primarily a special-order product that was adapted to a customer's body, after measuring his or her physical dimensions. More recently, the immediate use of an AFO following physical impairment has been considered desirable, given its medical benefits. Accordingly, there has been an increased need for standardized, off-the-shelf products; however, it can be difficult to customize an existing AFO, because a user's medical condition can change daily. As a result, there is increasing interest in standardized products that feature dimensions that can be adjusted in response to physical changes that occur after the product has been manufactured and delivered. In response to this interest, Kawamura Gishi decided to develop a new standardized AFO.

For the development of GS, Kawamura Gishi has employed a novel technology using which the academic researcher working on the AFO has already developed a prototype. This NPD has been funded by New Energy and Industrial Technology Development Organization (NEDO), which is Japan's largest public research and development management organization. GS has a unique oil damper to generate resistance to prevent excessive plantar flexion of the ankle joint and move freely to dorsiflexion, while the ankle joint of the traditional AFOs is rigid to stabilize the ankle and maintain clearance in swing. Moreover, GS's flexible design is such that as the user's medical condition changes, it can be adjusted. These novel functions of GS, however, have been considered beyond common sense in the industry. This is illustrated by the following quotation, from the chief engineer of the $\mathrm{R} \& \mathrm{D}$ division:

'When I presented this idea in an academic conference, most of the researchers and practicians condemned us. Moreover, the salespersons within the organization were unwilling to deliver it to customers.'

\section{Service Package Design}

Traditional AFOs require maintenance and rehabilitation services to adjust in response to physical changes. In traditional AFOs, the strength of the braking force is changed by adjusting its material thickness or by trimming; fine adjustments are practically difficult. Such adjustments cannot be restored and depend on the tacit knowledge of servicepersons. GS, on the other hand, has a unique hydraulic damper that can be adjusted using a single tool; this can modify the strength of the braking force and the angle at which it takes effect. The novel technology enables the service to radically change. This is illustrated by the following quotation, from the chief engineer of the $\mathrm{R} \& \mathrm{D}$ division:

'In the traditional AFO, as prosthetists or servicepersons ask a doctor and a physical therapist about a user's physical condition and adjusted the AFO using their tacit knowledge. They ignored users' feedback. There were no evidences to evaluate the effects of adjustments and their adjustments could not compare with other cases... 
I wanted the users to participate in the team for rehabilitation... I think an ideal rehabilitation service is based on a discussion in which users, doctors, physical therapist and prosthetists all participate. GS realizes such team rehabilitation service by offering the evidence to compare their physical conditions.

Despite being a technologically innovative and novel service package, GS sales did not grow initially. NPD members thought that the failure of sales was caused by its product appearance, which did not differ from that of existing AFOs. This is illustrated by the following quotation, from the manager of the manufacturing division:

'The reasons for slow sales are its large size, how it makes wearing shoes difficult, and its low-quality aesthetics. '

The older-style model puts visual stress on users because the shape of the foot-ankle assembly necessitates that they wear custom-tailored shoes. Using an AP like an AFO and custom-tailored shoes makes one's disability visible to others (Correia de Barros, Duarte, \& Cruz, 2011). For this reason, the traditional AFO elicits negative emotions from users. Thus, the NPD team of GS are determined to improve AFOs and to involve in the process an industrial designer, who has won various design awards such as the Red Dot Award.

\section{Product Language Design}

The development of GSD has been funded by NEDO again. The designer was involved in this NPD and initiated the development of the concept to change the changing users' cognitive responses. First, he focused on the users' cognition of rehabilitation, and he used a metaphor to transform its meaning. This is illustrated in the following quotation.

'I think of rehabilitation a sort of "sport", and an AFO is a piece of equipment used to promote exercise among users. I, therefore, want users to obtain a 'sporty' impression from the outward appearance of the AFO'.

Here, the designer uses a metaphor, in which rehabilitation is equated with 'playing sports' and an AFO with 'sports equipment'. The intangible product attributes involved are as follows.

\section{Aesthetic Impression}

The GSD has a titanium frame, and its shape resembles a streamlined skeleton. This material and shape helps express 'dynamic stability', which implies a sense of vitality. Biological forms that resemble human figures tend to attract and fascinate consumers (Chang \& Wu, 2007). Moreover, colour is a factor that enriches the sensory experience and significantly affects human emotions (Da Silva, Crilly, \& Hekkert, 2015). For this reason, the GSD is offered in three different colours (see Figure 2). The classic colour of the existing AFO (Figure 6) is ideal because it matches the skin tone of many people, and thus, camouflages the device. Then, to encourage users to 'show off' their new AFO, the designer gave them the opportunity to select their favourite colour.
Figure 6. Comparison of a classic AFO (left) and GSD (right)

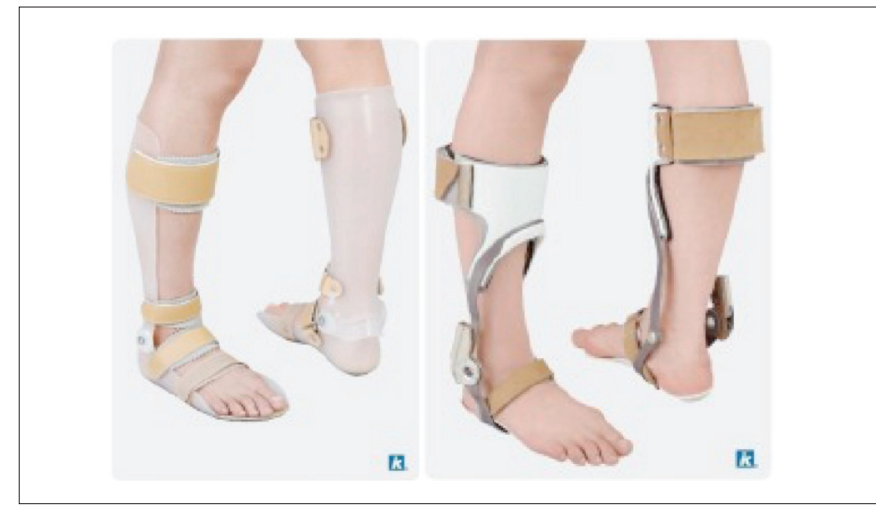

\section{Semantic Interpretation}

Streamlining the foot-ankle assembly made it possible for users to wear a variety of shoes on the top of GSD. The shape is similar to a shoe innersole; this allows users to wear their shoes, rather than custom-made ones. Additionally, GSD is shaped like a sandal (Figure 5). A user can put the product on, without raising his or her foot, by tilting the frame forward and inserting the foot from the rear. Users can perceive GSD's ease of wear from its appearance, and this motivates them to wear their own favourite shoes with it. Moreover, material selection determines a product's range of function, durability, and user experience (van Kesteren, Stappers, \& de Brujin, 2007). While the frame material of the existing AFO is plastic, the GSD designer selected titanium, which is not only lightweight and durable but also perceived by users as a strong material.

Figure 7. How to wear the GSD

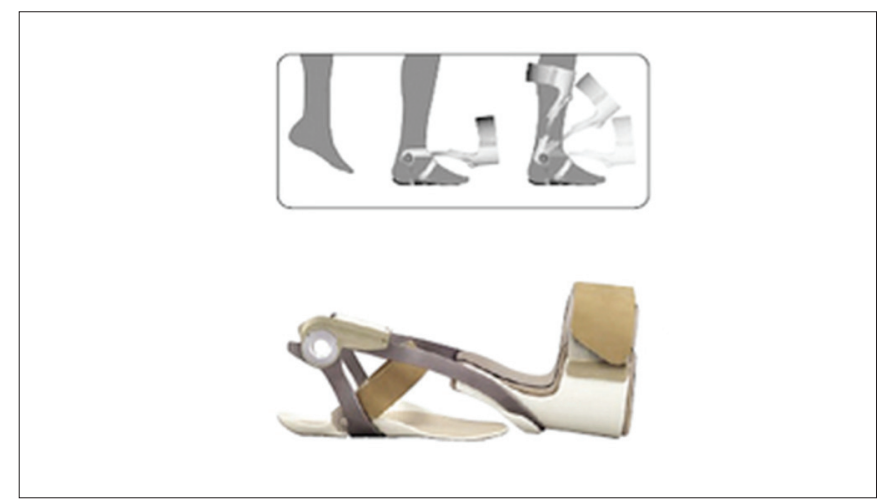

\section{Symbolic Association}

AFO users require rehabilitation to improve their medical condition; this might involve unpleasant affective states (Markussen, 2009). The GSD designer, who has experience in designing sports equipment, wanted to portray this rehabilitation as 'playing a sport'; he encouraged users to evoke a 'sporty' impression via the GSD's physical appearance. Correia de Barros et al. (2011) noted that APs are associated with negative stereotypes, and they suggest that designers work on them to reduce the associated stigma. Design attributes allow users to categorize products (Eisenman, 2013). The GSD's aesthetic 
impression and semantic interpretation work together to transform the user's categorization of the AFO and influence the social values it may connote.

\section{Service Interaction Design}

The product's appearance is the first point of contact with the users, and it should be used to attract them to the associated service. For users of the older-style AFO, the product was something they tried to hide, on account of social concerns (e.g., stigma). Consumers are motivated to avoid products that generate displeasure (Desmet \& Hekkert, 2007). For these reasons, the very appearance of the AFO discouraged them from undergoing rehabilitation, and thus, impeded improvements to their medical condition. Therefore, the designer explored ways to transform users' negative emotions to positive ones and to motivate them to undertake rehabilitation. This chain of events is seen in the following quotation.

'The motivation of a user is an important factor in solidifying the commitment to rehabilitation. Design has the power to motivate users and help enhance their rehabilitation effect'.

GSD has an aesthetic appeal and highly practical qualities. It elicits positive emotional responses from users, and thus, acts as a cue in expanding their sphere of action and attracting them to the rehabilitation service. Additionally, the designer emphasized the need to visualize the effect of rehabilitation; this was seen with Nike+, which allows users to visualize the effects of their running. This is illustrated in the following quotation by the designer.

'A player's motivation to improve his or her ability is crucial to continue to train hard. In the case of rehabilitation, patients are not concerned about winning or losing. I think it is important to visualize effects of rehabilitation'.
Kawamura Gishi developed an interaction device as a service interaction that enables users to quantitatively understand their medical condition on the spot, called Gait Judge System (GJS). Kawamura Gishi also offered maintenance service, adjusting its material thickness or trimming the plastic body, with the traditional AFO and rehabilitation instructions using the adjusted AFO. Such adjustments cannot be restored and depend on the tacit knowledge of the serviceperson. This means that it is difficult for the users to understand the effect of rehabilitation. When users better understand their medical condition, they respond more positively to the ensuing rehabilitation program. Moreover, GJS urged to deliver the rehabilitation service by the rehabilitation team; this program comprised medicine, a rehabilitator, and a Kawamura Gishi serviceperson. GJS enabled them to plan the rehabilitation program based on quantitative evidences.

\section{Technology Epiphany}

GSD won the Red Dot Design Award and Japan's most prestigious design award (Good Design Award). The review committee of the Good Design Awards reportedly appreciated GSD as (1) having an innovative product concept, (2) a novel product form, (3) high competitive technology, and (4) a longer product life and ease-of-use. After launching GSD, the total monthly sales of GS and GSD exceeded 300 units. This is illustrated by the following quotation, from the manager of the manufacturing division:

'When we offer a novel product to consumers, we must properly explain its use. Above all, we learn that a welfare product must be one that encourage users to use...The diffusion of GSD makes us find other medical cases to which its broadly applicability is beyond our expectation'

Moreover, Kawamura Gishi offered the information related to the technology of GSD on its website. It reported that the number of academic papers discussing the effect of GSD has increased in recent years (Figure 8) after launching GSD (November, 2005). This means that the novel technology is accepted by the society.

Figure 8. Number of academic papers

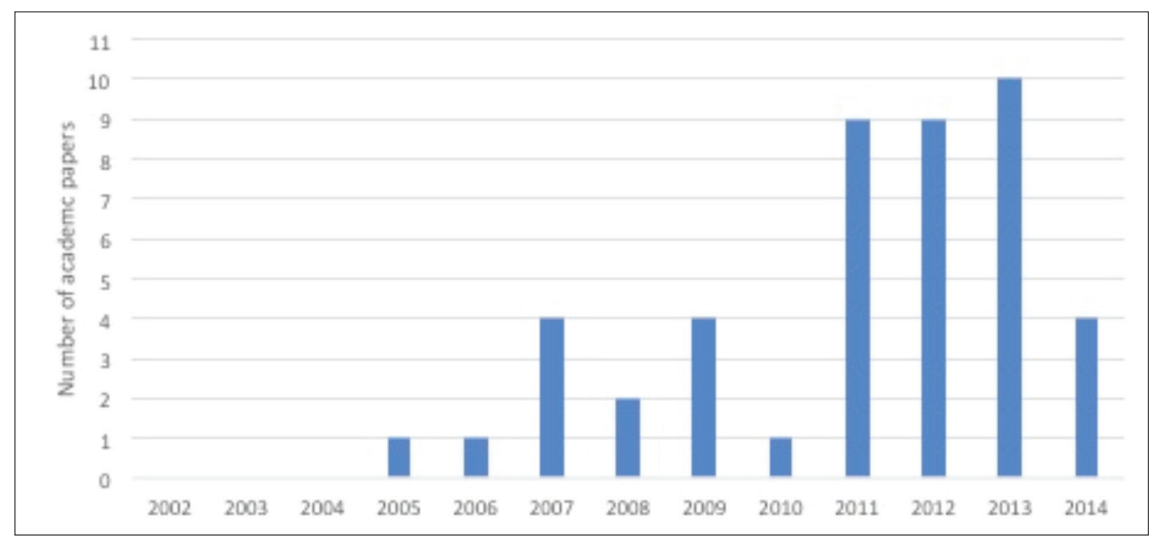

ISSN: 0718-2724. (http://jotmi.org) 


\section{Discussion}

A product's meaning for any given person is likely to be affected by that person's first-sight response to design attributes and from the longer-term psychological processes that subsequently ensue (Eisenman, 2013). GSD and the related rehabilitation service contribute to changing first- and second-order meanings. First-order meaning works as a categorical meaning at the user's first point of contact. Users categorize GSD as a piece of sports equipment, on account of its aesthetic impression and semantic interpretation. Moreover, the positive aesthetic impression and the ability to wear one's own favourite shoes release the product from what might otherwise be a negative societal connotation, and thus, help reduce user stigma (Correia de Barros et al., 2011). In this process, users associate with the selfexpressive symbolism.

Moreover, the rehabilitation service offers the intended context in which users use GSD. GJS and the rehabilitation team work together to offer users the experience of improving their ability to walk. The store of experience with GSD works as a second-order meaning and helps in the dynamic reconstruction of interpreting GSD. In this process, the same product meaning is shared by the company and the product's users. As mentioned previously, Dell'Era and Verganti (2011) stressed that collaboration among companies helps in disseminating product meaning; in this case, instead of companies' collaboration, the service itself is useful in sharing product meaning with users. Figure 9 shows the comprehensive model developed in this study.

Figure 9. Research model

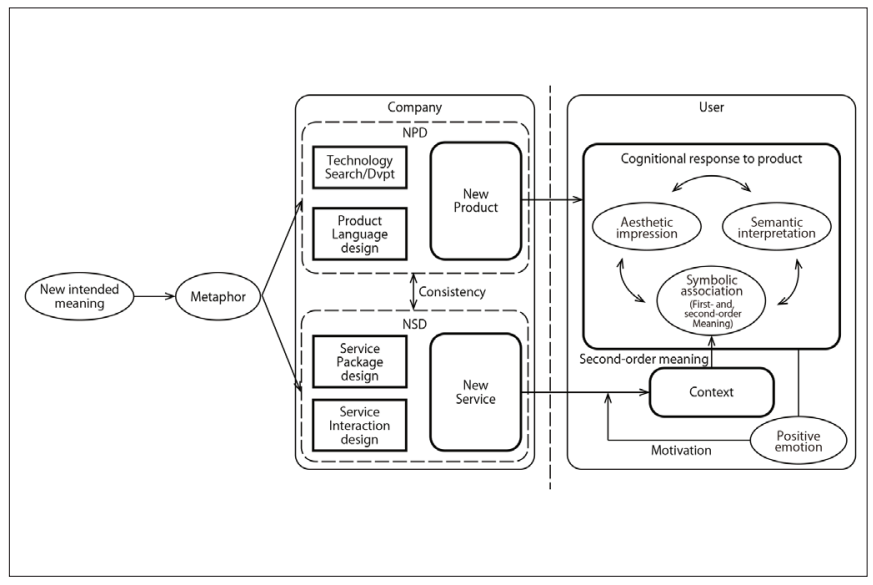

However, this exploratory case shows that even if the novel technology and service package is offered, the integrated product and service does not have the sales potential without the positive emotion that the product appearance elicits. GS's product appearance evoked negative emotion in users. This discouraged them to get the service. The company, as a result, could not offer additional information and experience to change the second-order meaning. Thus, this finding provides a better understanding of the importance of product language in the development of an integrated product and service. This study stresses that users make sense of a novel technology during their first contact with a product and a subsequent reconstruction process.
This finding also emphasizes on the consistency between the first-order meaning assigned to the product language and the second-order meaning that users reconstruct in the context. In this case, the designer used a metaphor-to use an AFO was analogous to playing sports. Existing studies show that metaphor usage is effective in conveying a specific meaning through product appearance (Crill, Moultrie, \& Clarkson., 2004). Moreover, Zomerdijk and Voss (2011) suggested that metaphor usage can guide the development of experimental services. The current study finds that metaphor usage in developing an integrated product and service helps maintain consistency between the intended meaning assigned to the product language and the intended context offered by the service.

Verganti (2011, p. 367) emphasized that companies search for 'how a new technology enables the creation of products and services that are more meaningful for people. This finding shows that customers accepted the novel technology when the product's appearance was changed, especially reducing the stigma and providing the unique rehabilitation service. As mentioned above, although provoking positive emotions is likely to be a key factor for the achievement of technology epiphany, only a few studies on integrated products and services have focused on it. For example, Stacey and Tether (2015) found that designers paid attention to the positive emotional chain reactions in the processes of new PSS development. This study also found that the designer drove the development of an integrated emotion-centric product and service in technology epiphany.

\section{Conclusion}

This study sought to answer RQs regarding how an integrated product and service contribute to achieving technology epiphany. The following are the three conclusions of this study:

- Positive emotions that product appearance elicits from users motivate them to get subsequent services.

- A service is an opportunity to share the intended meaning with users and guide them to reconstruct second-order meaning that a company intends.

- Using metaphors contributes to maintaining consistency between a product and service.

- A designer drives the development of an integrated emotioncentric product and service in technology epiphany.

Technology epiphany means that users give a novel meaning to a new technology (Verganti, 2011). The study emphasizes offering an integrated product and service is an effective way to achieve technology epiphany.

From a theoretical point of view, the comprehensive model has an implication for future studies. Barczac (2012) stressed that research regarding product/service hybrid offerings is an issue that might be interesting and useful for academicians to pursue. This study concludes that technology epiphany requires an integrated offering of a product 
language as a first contact with users and a service as their dynamic reconstruction process. Traditionally, most studies have considered products separately from services. Although recent years have seen PSS, servitisation, or productisation (Baines et al., 2007), their studies have not focused on the perspective of IoM. The present model includes the intangible attribute as the key factor that promotes a deep understanding of the relationship between the integrated product and service and IoM. This implies that IoM is a synthesis of technology and service into new meanings. Moreover, this study contributes to the understanding of the designer's role in the development process of the integrated product and service. Many researchers emphasize on extending the role of designers in the process (Morelli, 2003). This study shows that technology epiphany results from collaboration between designers and other participants. Using metaphors is likely to be one of the ways to assist their collaboration.

From a practical point of view, the present model offers managerial guidance to design integrated products and services to elicit emotional satisfaction in users. Existing studies regarding integrated products and services have neglected factors related to emotions in their design methods. This exploratory case study showed that product appearance is an enabler to motivate users to use the service as well as convey the meaning as the product language.

This exploratory study develops a theory on IoM and an integrated product and service by combining observations from the existing literature and the chosen case study theoretically. Thus, it contributes to developing a better understanding of IoM. As a next step, future research may examine the theoretical model, especially the role of designers and the relationship between first- and second-order meanings using a large sample of data.

\section{Biographical notes}

Satoru Goto is currently an assistant professor at Toyo Gakuen University, Japan. He received his $\mathrm{PhD}$ in the Technology Management from Ritsumeikan University. He has an undergraduate degree and a master's degree in Science and Engineering from Ritsumeikan University. His current research interests are product-service systems and innovation of meaning. His articles have been published in the International Journal of Business and Systems Research (IJBSR). Further, he translated Design Driven Innovation, which was published by Robert Verganti in 2009, to Japanese.author:

\section{References}

Barczak, G. (2012). The future of NPD/innovation research. Journal of Product Innovation Management, 29(3), 355-357.

Barczak, G. (2012). The future of NPD/innovation research. Journal of Product Innovation Management, 29(3), 355-357.

Bellini, E., Dell'Era, C., Frattini, F., \& Verganti, R. (2017). DesignDriven Innovation in Retailing: An Empirical Examination of New Services in Car Dealership. Creativity and Innovation Management, 26(1), 91-107.
Brodie, R. J., Hollebeek, L. D., Juric, B., \& Ilic, A. (2011). Customer engagement: Conceptual domain, fundamental propositions, and Implications for research. Journal of Service Research, 14(3), 252-271.

Buganza, T., Dell'Era, C., Pellizzoni, E., Trabucchi, D., \& Verganti, R. (2015). Unveiling the potentialities provided by new technologies: A process to smartphone app industry. Creativity and Innovation Management, 24(3), 391-414.

Candi, M. (2006). Design as an element of Innovation: Evaluating design emphasis in technology-based firms. International Journal of Innovation Management, 10(4), 351-374.

Candi, M., \& Saemundsson, R. J. (2011). Exploring the relationship between aesthetic design as an element of new service development and performance. Journal of Product Innovation Management, 28(4), 536-557.

Chang, W. C., \& Wu, T. Y. (2007). Exploring types and characteristics of product forms. International Journal of Design, 1(1), 3-14.

Correia de Barros, A., Duarte, C., \& Cruz, J. B. (2011). The Influence of Context on Product Judgement - Presenting Assistive Products as Consumer Goods. International Journal of Design, 5(3), 99-112.

Crilly, N., Moultrie, J., \& Clarkson, P. J. (2004). Seeing things: consumer response to the visual domain in product design. Design Studies, 25(6), 547-577.

Da Silva, O., Crilly, N., \& Hekkert, P. (2015). How people's appreciation of products is affected by their knowledge of the designers' intentions. International Journal of Design, 9(2), 21-33.

Dell'Era, C., \& Verganti, R. (2011). Diffusion processes of product meanings in design-intensive industries: Determinants and dynamics. Journal of Product Innovation of Management, 28(6), 881-895.

Desmet, P., \& Hekkert, P. (2007). Framework of product experience. International Journal of Design, 1(1), 57-66.

Eisenhardt, K. M. (1989). Building theories from case study research. The Academy of Management Journal, 14(4), 532-550.

Eisenman, M. (2013). Understanding aesthetic innovation in the context of technological evolution. Academy of Management Review, $38(3), 332-351$.

Farhana, M., \& Bimenyimana, E. (2015). Design driven innovation as a differentiation strategy - in the context of automotive industry. Journal of Technology Management and Innovation, 10(2), 24-38.

Gemser, G., \& Leenders, M. A. A. M. (2001). How integrating industrial design in the product development process impacts on company performance. Journal of Product Innovation Management, 18(1), 28-38.

Gorb, P., \& Dumas, A. (1987). Silent Design. Design Studies, 8(3), 150-156. 
Goto, S., \& Ishida, S. (2014). Technology development strategy for radical product meaning. International Journal of Business and System Research, 8(4), 402-418.

Hoegg, J., \& Alba, J. W. (2011). Seeing Is believing (too much): The influence of product form on perceptions of functional performance. Journal of Product Innovation Management, 28(3), 346-359.

Kazmierczak, E. T. (2003). Design as meaning making: From making things to the design of thinking. Design Issues, 19(2), 45-59.

Kembaren, P., Simatupang, T. M., Larso, D., \& Wiyancoko, D. (2014). Design Driven Innovation Practices in Design-Preneur Led Creative Industry. Journal of Technology Management and Innovation, 9(3), 91-105.

Kleine III, R. E., \& Kernan, J. B. (1991). Contextual Influences on the meanings ascribed to ordinary consumption objects. Journal of Consumer Research, 18(3), 311-324.

Krippendorff, K. (1989) On the essential contexts of artefacts or on the proposition that 'Design Is making sense (of things)'. Design Issues, 5(2), 9-38.

Levy, S. J. (1959). Symbols for sale. Harvard Business Review, 37(JulyAugust), 117-124.

Markussen, T. (2009). Bloody robots as emotional design: How emotional structures may change expectations of technology use in hospitals. International Journal of Design, 3(2), 27-39.

Maussang, N., Zwolinski, P., \& Brissaud, D. (2009). Product-service system design methodology: from the PSS architecture design to the products specifications. Journal of Engineering Design, 20(4), 349-366.

Morelli, N. (2002). Designing product/service systems: A methodological exploration. Design Issues, 18(3), 3-17.

Norman, D. A., \& Verganti, R. (2014). Incremental and radical innovation: Design research vs. technology and meaning change. Design Issues, 30(1), 78-96.

Pacenti, E., and Sangiorgi, D. (2010). Service design research pioneers: An overview of service design research developed in Italy since the 1990s. Design Research Journal, 1(10), 26-33.

Pedgley, O. (2009). Influence of stakeholders on industrial design materials and manufacturing selection. International Journal of Design, 3(1), 1-15.

Pinch, T., \& Bijker, W.E. (1987). The social construction of facts and artefacts: Or how the sociology of science and the sociology of technology might benefit each other. In W. E. Bijker, T. P. Hughes, \& T. Pinch (Eds.), The social construction of technological systems: New directions in the sociology and history of technology (pp. 17-50). Cambridge, MA: The MIT Press.
Rha, J.-Y. (2012). Customer satisfaction and qualities in public service: an intermediary customer perspective. The Service Industries Journal, 32(12), 1883-1900.

Shostack, L. (1984). Designing services that deliver. Harvard Business Review, 62(1), 133-139.

Simoni, M., Cautela, C., \& Zurlo, F. (2014) Product Design Strategies in Technological Shifts: An Explorative Study of Italian Design-Driven Companies. Technovation, 34(11), 702-715.

Stacey, P., \& Tether, B. (2015). Designing emotion-centered product service system: the case of a cancer care facility. Design Studies, 40, 85-118.

Rampino, L. (2011). The Innovation Pyramid: A Categorization of the Innovation Phenomenon in the Product-design Field. International Journal of Design, 5(1), 3-16.

Ulrich, K. T., \& Eppinger. S. D. (2004). Product Design and Development (3rd ed.). McGraw-Hill.

van Kesteren, I. E. H., Stappers, P. J., \& de Bruijn, J. C. M. (2007). Materials in product selection: Tools for including user-interaction aspects in materials selection. International Journal of Design, 1(3), 41-55.

Verganti, R. (2008). Design, meanings, and radical innovation: A metamodel and a research agenda. Journal of Product Innovation Management, 25(5), 436-456.

Verganti, R. (2011). Radical design and technology epiphanies: A new focus for research on design management. Journal of Product Innovation Management, 28(3), 384-388.

Verganti, R. (2017). Overcrowded: Designing Meaningful Products in a World Awash with Ideas. Cambridge, MA: The MIT Press.

Verganti, R., \& Buganza, T. (2005). Design inertia: Designing for lifecycle flexibility in internet-based services. Journal of Product Innovation Management, 22(3), 223-237.

Yin, R. K. (1994). Case study research: Design and methods (2nd ed.). Thousand Oaks, CA: Sage Publications.

Zomerdijk, L. G., \& Voss, C. A. (2011). NSD processes and practices in experiential services. Journal of Product Innovation Management, 28(1), 63-80. 
